\title{
Variations in the mussel population of the Dutch Wadden Sea in relation to monitoring of other ecological parameters*
}

\author{
N. Dankers \& K. Koelemaij \\ Research Institute for Nature Management; P.O. Box 59, 1790 AB Den Burg, Texel, \\ The Netherlands
}

\begin{abstract}
The pattern of distribution of intertidal mussel beds is relatively constant over a number of years although their surface area can vary greatly. The abundance of mussels shows much greater fluctuations. In the western part of the Dutch Wadden Sea, west of the Terschelling tidal divide, the amount of mussels on natural beds fluctuated between 1 and 24 million $\mathrm{kg}$ fresh weight during the years 1949 to 1988 . In the eastern part of the Dutch Wadden Sea the biomass varied between 5.5 and 180 million $\mathrm{kg}$. The influence of the mussels on the ecosystem therefore can be very different between years. When many mussels are present the whole watermass can be filtered every few days. In years with few mussels present the filtering may take one month. It is argued that monitor programmes for a.o. nutrients, chlorophyll and growth rates of benthic organisms are of limited value if there is no indication about the total amount of mussels in the area.
\end{abstract}

\section{INTRODUCTION}

The mussel Mytilus edulis is a natural inhabitant of the Wadden Sea. In summer, larvae settle on suitable substrates such as dikes, chains, ropes, old mussel beds, tubes of Lanice conchilega and sometimes on bare sand. Mussels can occur in such densities that they can filter the whole watermass of an estuary through their gills in a matter of days (Dankers et al., 1989). Mussel beds have considerable influence on the estuarine ecosystem. They remove silt and organic matter from the watermass and stimulate mineralization processes. The mussel beds produce nutrients such as ammonia and phosphate, and may stimulate primary production. The magnitude of the influence of the mussels on the ecosystem depends on the standing stock of the mussel population.

In this paper, the fluctuations in the mussel population will be investigated on the basis of estimates of standing stock or aerial coverage of previous investigations by various authors. The impact of the fluctuating mussel population on ecosystem parameters which are often monitored will be discussed.

Natural banks can be found in the littoral zone, but also subtidally. Mussel culture is practised on subtidal plots. When monitoring programs are envisaged, it is important to consider these three different populations because each requires specific monitoring

\footnotetext{
* Presented at the VI International Wadden Sea Symposium (Biologische Anstalt Helgoland, Wattenmeerstation Sylt, D-2282 List, FRG, 1-4 November 1988)
} 
techniques. In the Dutch Wadden Sea, $1200 \mathrm{~km}^{2}$ of tidal flats are present and $1220 \mathrm{~km}^{2}$ of subtidal areas. The area west of the Terschelling tidal divide, but excluding the Eyerlandse Gat between Texel and Vlieland, is referred to as the western part of the Wadden Sea which consists of $396 \mathrm{~km}^{2}$ of tidal flats and $1049 \mathrm{~km}^{2}$ subtidal area. Of the subtidal area, $70 \mathrm{~km}^{2}$. is covered by mussel culture plots. The eastern Wadden Sea is the area east of the Terschelling tidal divide exclusive of the Ems-Dollard estuary. The eastern Wadden Sea contains $804 \mathrm{~km}^{2}$ of tidal flats and $171 \mathrm{~km}^{2}$ of subtidal area.

\section{METHODS}

For the estimation of the distribution and abundance of the mussels several methods were used. The only quantitatively reliable information on the spatial distribution in the entire Wadden Sea is given by Dijkema (1989). His assessment was based on interpretation of aerial photographs from 1978. In 1966, Ente (pers. comm.) mapped some mussel beds in part of the Ameland region. In 1984, De Beer (pers. comm.) and in 1988, Hesselink \& Dodde (pers. comm.) produced maps on which the approximate locations of banks were indicated. In the present paper, information solely on the spatial distribution in the Ameland region was used.

Information on the abundance of mussels was obtained from several sources. Verwey (1952) published estimates for the western Wadden Sea as made by the fisheries inspector. Kamps (1962) measured the surface covered by mussels in the eastern Wadden Sea, also giving the density of the mussels on the beds. Beukema (1976; Beukema et al., 1978) quantitatively sampled the macrobenthic organisms on 99 transects of $1 \mathrm{~km}$ length in the Dutch Wadden Sea between 1971 and 1974. In 1977 he resampled the 48 transects in the western part of the Wadden Sea.

In 1987, Wensink \& Reitsma (pers. comm.) sampled almost all the intertidal mussel beds in the Dutch Wadden Sea. On the basis of their estimated average of $20000 \mathrm{~kg}$ mussels per ha and the surface area measured by Dijkema (1989), an estimate of the biomass present in 1978 was made. In 1988, the mussel beds in the Ameland area were investigated thoroughly by Hesselink and Dodde. On each mussel bed they measured the percentage substrate covered by mussels, and samples were taken in order to calculate the density of the mussels. On the basis of these measurements they were able to calculate the biomass of each bed.

In the subtidal area of the western Wadden Sea, the macrobenthos was investigated in 1981 by Dekker (1987). Only his results on the mussels outside the culture areas are used. An estimate of the mussels on the culture plots was made by Dankers et al. (1989). On the basis of the amount of seed mussels brought onto the plots, growth curves, estimated mortality and the amount of mussels harvested, the biomass for each month was calculated for the years 1984-1988.

\section{RESULTS}

In Figure 1 the location of the mussel beds in the area south of Ameland is presented. For the beds indicated by De Beer (pers. comm.) and Hesselink \& Dodde (pers. comm.) only the approximate location with regard to 1984 and 1988 is given and these beds are not drawn to scale because information on the shape of the beds is lacking. 


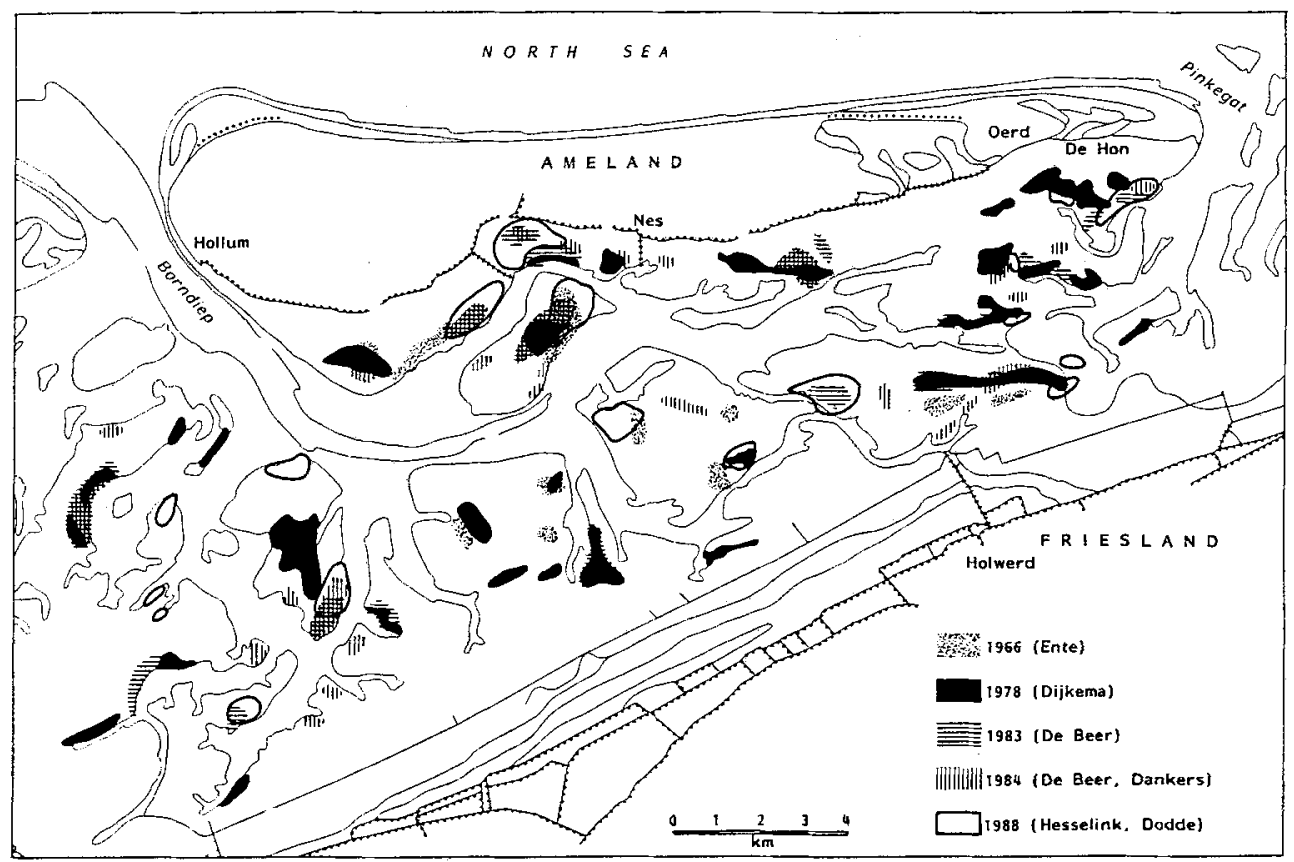

Fig. 1. The distribution of intertidal mussel beds in the Ameland region between 1966 and 1988

The map indicates that many beds were present at the same places as they were in 1978 and in the period between 1983 and 1988. In the period between 1978 and 1988 most beds disappeared more than once because of storms, ice and fishing. Sometimes, beds re-establish themselves within one year, but in other years spatfall is insufficient. Therefore, it may take several years before a bed appears again. Some 1978 locations no longer display any mussel beds. The beds have either disappeared completely from the area or now occur on nearby locations. Similar patterns are also observed in the rest of the Wadden Sea.

Historical information on the biomass of the mussels in the Dutch Wadden Sea is hardly available. Investigations by Hoek (unpubl.), Research Institute for Fisheries Investigations (unpubl.), Kuenen (1942), Maas Geesteranus (1942) and van Straten (1965) were not quantitative. Verwey (1952) is the first author who gives quantitative information based on estimates of the fisheries inspector. The quantitative information which was available in the literature or could be calculated on the basis of distribution maps (Dijkema, 1989) has been summarized in Table 1. In the fifties, the mussel biomass must have been considerably less than Verwey's estimate because in that period it seemed virtually impossible for the mussel farmers to obtain sufficient spat for their culture plots. For the eastern part of the Wadden Sea, Kamps (1962) gives a high estimate for 1961, but in 1963 almost all mussel beds disappeared because of the very severe winter (K.S. Dijkema, pers. comm.).

From the map of Dijkema (1989) it can be concluded that in 1978 the western Wadden Sea contained 854 ha of mussel beds and the eastern Wadden Sea 2505 ha. It is 
Table 1. Summary of the biomass estimates of the mussel population in the Wadden Sea (all values in $10^{6} \mathrm{~kg}$ fresh weight)

\begin{tabular}{|c|c|c|c|c|c|}
\hline \multirow{2}{*}{ Year } & \multirow[t]{2}{*}{ Author } & \multicolumn{3}{|c|}{ Western Wadden Sea } & \multirow{2}{*}{$\begin{array}{c}\text { Eastern } \\
\text { Wadden Sea } \\
\text { Littoral }\end{array}$} \\
\hline & & Littoral & Sublittoral & Culture & \\
\hline 1949 & Verwey (1952) & 16 & & & \\
\hline \pm 1955 & Kamps (1962) & & & & 45 \\
\hline 1961 & Kamps (1962) & & & & 180 \\
\hline $1971-72$ & Beukema (1976) & 7 & & & 142 \\
\hline 1977 & Beukema et al. (1978) & 24 & & & \\
\hline 1978 & $\begin{array}{l}\text { Wensink \& Reitsma } \\
\text { (pers. comm.) }\end{array}$ & 17 & & & 50 \\
\hline 1981 & Dekker (1987) & & 165 & & \\
\hline 1987 (spring) & $\begin{array}{l}\text { Wensink \& Reitsma } \\
\text { (pers. comm.) }\end{array}$ & 1 & & & 5.5 \\
\hline 1987 (autumn) & Beukema (pers. comm.) & 6 & & & \\
\hline $1977-87$ & Dankers et al. (1989) & & & $33-136$ & \\
\hline
\end{tabular}

assumed that on each ha of a mussel bed $20000 \mathrm{~kg}$ mussels are present (Wensink \& Reitsma, pers. comm.). This value might be too low because when Wensink \& Reitsma did their investivation in 1987 the mussel beds had suffered from several ice winters. In 1988, Hesselink \& Dodde (pers. comm.) found on average $61000 \mathrm{~kg}$ per ha on the mussel beds under Ameland, but that value is considered relatively high because in the autumn of 1987 a very good spatfall occurred. In years with good spatfall the autumn biomass in an extensive area can be three times as high as the spring biomass (Beukema, unpubl.).

The information presented in Table 1 indicates that large variations in the biomass of mussels occur between years, even when the surface area is relatively constant. The area south of Ameland contained 258 ha of mussel beds in 1987 with a biomass of $5.4 \times 10^{6} \mathrm{~kg}$. In spring 1988, the area had slightly increased to $273 \mathrm{ha}$, but the biomass increased to $16.6 \times 10^{6} \mathrm{~kg}$ (Hesselink \& Dodde, pers. comm.). This investigation also made it clear that large variations can occur within a year. Of the $16.6 \times 10^{6} \mathrm{~kg}$ present in early June, $60 \%$ were fished away by July. The Balgzand tidal flat is the only region for which a good time series of biomass estimates is available. Beukema investigated 15 transects each spring since 1969. Mussel beds sometimes occurred in the transects. The mean mussel biomass on the transects varied between $0.3 \mathrm{~g} / \mathrm{m}^{2}$ and $6 \mathrm{~g} / \mathrm{m}^{2}$.

In the sublittoral regions of the western part of the Wadden Sea two different groups of mussels should be considered: the mussels in the culture areas and the mussels on natural beds. Spatfall occurs in many places. On subtidal mussel beds with high densities, the one-year old spat is fished by the mussel growers and introduced onto the culture plots. On the culture plots, the mussels are left for approximately $1 \frac{1 / 2}{2}$ years until they reach commercial size.

The locations of the culture plots are well known, and they have shifted only marginally over the years. Knowledge on the locations of the natural subtidal beds is limited. On the basis of side scan sonar observations some indications about these 
locations were obtained in June 1985. Observations of vessels fishing for mussel spat indicate that spat beds tend to occur in the same places each year although sometimes beds are not present in areas where they normally occur.

Quantitative information on the biomass of the sublittoral natural beds is limited to one investigation in 1981-1982 (Dekker, 1987). On the basis of more than 400 samples Dekker concluded that $165 \times 10^{6} \mathrm{~kg}$ mussels were present outside the culture plots in the sublittoral regions of the western part of the Wadden Sea. Nothing is known about the variations within or between years.

The amount of mussels on the culture plots between 1984 and 1988 is presented in Figure 2 (Dankers et al., 1989). In years with few storms the biomass is possibly higher, while after severe storms it can be lower than the biomass presented in Figure 2.

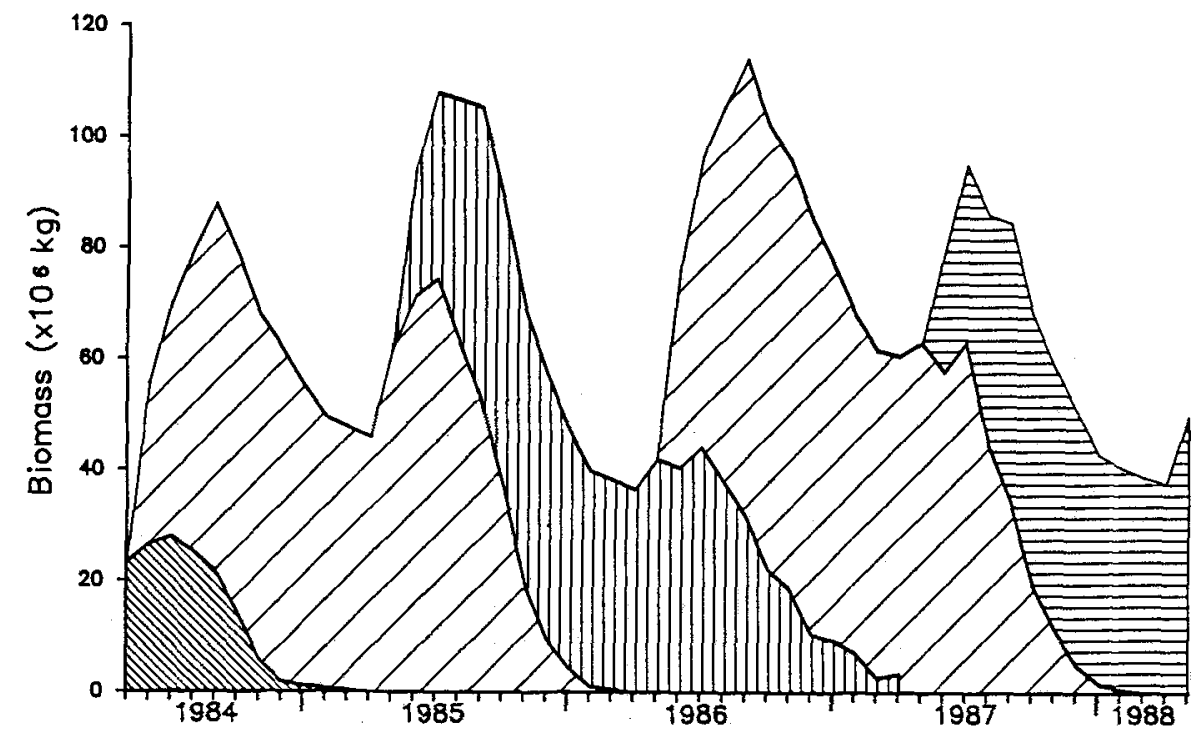

Fig. 2. The calculated biomass of mussels on the culture plots in the Dutch Wadden Sea (from Dankers et al., 1989). The different hatchings indicate different year classes

\section{DISCUSSION}

It is clear that estimates of the biomass of the mussel population in different years vary greatly. This is only partly due to the methods the different authors used in the calculations.

The large variations are caused not only by adverse environmental factors such as storms and ice, but also by fishing, as well as by favourable factors promoting spatfall. One reason for monitoring is to get an early impression of unwanted changes so that management practices can be designed that can influence future developments.

When fluctuations are caused by weather conditions it is not very important to monitor mussel densities because management cannot influence the weather. Only where fishing practices influence mussel beds could a monitoring program be useful in 
order to provide the managers with information which can be used in regulations to ensure that old mature mussel beds remain, and that overfishing does not take place.

However, mussels often occur in such densities that they influence the whole ecosystem. In the western part of the Wadden Sea there are so many mussels that they can pump the whole watermass through their gills within one week. They consume approximately $30 \%$ of the local primary production and much more is laid down in the pseudofaeces (Dankers et al., 1989).

In areas where no mussel culture exists the influence of the mussel population can also be important. In the area south of Ameland, at mean tide level, the water volume is $548 \times 10^{6} \mathrm{~m}^{3}$ (Kool et al., 1984). When $20 \times 10^{6} \mathrm{~kg}$ mussels are present these mussels pump approximately $62 \times 10^{6} \mathrm{~m}^{3}$ per day (Dankers et al., 1989). Therefore, they can pump the whole volume through their gills every 8.8 days. In years with low biomass $(5 \times$ $10^{6} \mathrm{~kg}$ in 1987), it would take around one month to filter the whole water volume. On the other hand there will be years with $40-50 \times 10^{6} \mathrm{~kg}$ mussels and accordingly the water is filtered every few days.

Mussels influence many important ecological parameters. Each square metre of a mussel bed can consume 15-55 mg chlorophyll per hour (Dame \& Dankers, 1988). On average, this means an hourly uptake of $2 \mathrm{mg}$ chlorophyll-a per $\mathrm{kg}$ mussels. Assuming a summer concentration of $10 \mathrm{mg}$ chlorophyll-a $\mathrm{m}^{3}$, the Ameland region contains $5500 \mathrm{~kg}$ chlorophyll-a as phytoplankton. In a year with high mussel density $80 \mathrm{~kg}$ of chlorophyll-a can be consumed per hour, equivalent to the whole phytoplankton biomass within three days. Parameters like chlorophyll, nutrient concentrations, primary production and suspended matter are important in monitoring programmes, but it is clear that the results of the monitoring can only be interpreted correctly when the extent of the influence of the mussels is known. Mussels reduce the amount of food available for other organisms. Many of these organisms are monitored, and variations in abundance and growth are thought to be correlated with eutrophication and primary production. It is impossible to draw conclusions about these relations when the extent of the influence caused by the mussel population is unknown.

Monitoring of the culture plots is recommended and should be carried out by the fisheries ministry; the services responsible for issuing permits to fish on natural mussel beds should also bear the responsibility of monitoring the natural beds.

It is also recommended that international cooperation is sought in the development of remote sensing techniques for the monitoring of natural beds.

Acknowledgements. We would like to thank B. Reitsma, J. Wensink, W. Henselink, M. Dobbe and the crews of the patrol vessels 'Krukel' and 'Phoca' for their investigations in often bad environmental conditions. J. Beukema and K. Dijkema provided some previously unpublished data. W. Wolff and J. Brouns critically read through an earlier version of the manuscript and their comments improved the clarity greatly.

\section{LITERATURE CITED}

Beukema, J. J., 1976. Biomass and species richness of the macro-benthic animals living on the tidal flats of the Dutch Wadden Sea. - Neth. J. Sea Res. 10, 236-261.

Beukema, J. J., de Bruin, W. \& Jansen, J. J. M., 1978. Biomass and species richness of the macrobenthic animals living on the tidal flats of the Dutch Wadden Sea: long-term changes during a period with mild winters. - Neth J. Sea Res. 12, 58-77. 
Dame, R. F. \& Dankers, N., 1988. Uptake and release of materials by a Wadden Sea mussel bed. - J. exp. mar. Biol. Ecol. 118, 207-216.

Dankers, N., Koelemaij, K. \& Zegers, J., 1989. De rol van de mossel en de mosselcultuur in het ecosysteem van de Waddenzee. Research Institute for Nature Management, Texel, $66 \mathrm{pp}$.

Dekker, R., 1987. The importance of the subtidal macrobenthos as a food source for the Wadden Sea ecosystem. - Biol. Meddr, 37, 27-36.

Dijkema, K. S., 1989. Habitats of the Netherlands, German and Danish Wadden Sea. Research Inst. for Nature Management/Veth foundation, Texel, $25 \mathrm{pp}$.

Kamps, L. F., 1962. Mud distribution and land reclamation in the eastern Wadden shallows. Rijkswaterstaat Commun. 1962, 1-73.

Kool, G., Peereboom, R., Lieshout, M. F. \& de Boer, M., 1984. Waterbeweging westelijke Waddenzee: verloop natte en droge overvlakten en kombergingen. - Rijkswaterstaat studiedienst Hoorn. - Nota WWKZ-84.HOO9, 1-13.

Kuenen, D. J., 1942. On the distribution of mussels on the intertidal sand flats near Den Helder. Archs. neerl. Zool. 6, 117-160.

Maas Geesteranus, R. A., 1942. On the formation of banks by Mytilus edulis L. - Archs neerl. Zool. 6, 283-326.

Straaten, L. M. J. U. van, 1965. De bodem der Waddenzee. In: Het Waddenboek. Ed. by J. Abrahamse. Tieme, Zutphen, 75-151.

Verwey, J., 1952. On the ecology of distribution of cockle and mussel in the Dutch Wadden Sea. Their role in sedimentation and the source of their food supply. With a short review of the feeding behaviour of bivalve molluscs. - Archs neerl. Zool. 10, 171-239. 